\title{
Sociología conversa en los siglos XV y XVI: La dinámica de las familias manchegas
}

Vincent PARELLO

Universidad de Montpellier III

Los individuos de los que voy a hablar en el presente artículo tienen la misma ascendencia y comparten un mismo destino, o sea que son todos convertidos de judíos y descendientes de condenados por la Inquisición por «crimen de herejía y apostasía». Constituyen un subgrupo dentro del conjunto de la sociedad conversa, la cual forma a su vez un subgrupo dentro de la sociedad mayoritaria cristiana vieja. A estos descendientes de condenados se les llamaba «inhábiles», ya que las ordenanzas del Inquisidor General Torquemada (1484) y las pragmáticas de los Reyes Católicos (1501) les excluían de los oficios públicos y de los beneficios eclesiásticos hasta la segunda generación en línea masculina y la primera en línea femenina, y les imponían además algunas interdicciones suntuarias y honoríficas como llevar seda, oro o plata, montar a caballo, traer armas, etc. ${ }^{1}$. En el subgrupo de los «inhábiles» podemos distinguir por lo menos dos categorías de personas: 1) los conversos reconciliados por el tribunal toledano a finales del siglo $\mathrm{XV}$ en los años 1485-1495; y 2) los hijos y nietos de los conversos condenados, es decir relajados en presencia, en ausencia o post mortem por la Inquisición.

${ }^{1}$ J. P. DEDIEU, «Hérésie et pureté de sang: l'incapacité légale des hérétiques et de leurs descendants en Espagne aux premiers temps de l'Inquisition», en Pouvoirs et société dans l'Espagne moderne (Toulouse 1993) págs. 161-176. 
Si bien la muerte de los conversos reconciliados anulaba los efectos de la inhabilitación y favorecía la asimilación de las generaciones futuras, en cambio, los descendientes de relajados sufrieron repercusiones legales hasta finales del siglo XVI y, en algunos casos, principios del siglo XVII. En el seno de la sociedad conversa, los «inhábiles» constituían pues un subgrupo minoritario desde un punto de vista cuantitativo y menospreciado desde un punto de vista cualitativo.

A través de las listas de los conversos del arzobispado de Toledo habilitados por la Inquisición en 1495 y 1497 y de las causas de «inhábiles» que fueron multiplicándose entre 1525 y 1575 , podemos hacernos una idea bastante fidedigna de la evolución sociológica de esta comunidad etnicorreligiosa y contemplar su fuerte dinamismo económico ${ }^{2}$.

Aunque los testimonios de los contemporáneos expresan más el odio religioso, racial y clasista que la serenidad y la objetividad histórica, resultan sumamente interesantes a la hora de analizar el lugar que ocupan los judeoconversos en la sociedad española de la época. Tanto Andrés Bernáldez, cronista de los Reyes Católicos, como Palencia, cronista de Enrique IV -aunque con menos virulencia- subrayan el dinamismo social de los judeoconversos durante el siglo XV. Según estos autores son individuos arrogantes, orgullosos, que arruinan a las capas populares por la práctica del préstamo y de la usura, que se dedican al comercio con toda impunidad, y que además han conseguido infiltrarse en los medios eclesiásticos, las esferas de la administración real, municipal y señorial. Dicho dinamismo social se traduce también por un rechazo de las tareas manua-

\footnotetext{
${ }^{2}$ Las listas de habilitados están en: AHN, Inq., leg. 120 exp. 36; AGS, Contaduría Mayor de Cuentas, primera época, leg. 100; AHN, Sección Clero, leg. 7218, núm. 4. Existen dos estudios muy conocidos sobre la conmutación de Toledo: F. CANTERA Burgos - P. LEÓN TEllo, Judaizantes del arzobispado de Toledo habilitados por la Inquisición en 1495 y 1497 (Madrid 1969), y T. AzCoNA, "Aspectos económicos de la Inquisición de Toledo en el siglo XV», en Simposio Toledo Renacentista (Madrid 1980) vol. I págs. 7-75. Recientemente, R. CARRASCo ha realizado una encuesta cuantitativa y estructural de los judeoconversos del arzobispado de Toledo a fines del siglo XV en «Solidaridades judeoconversas y sociedad local», en Inquisición y conversos, IIl Curso de Cultura Hispano-judía y Sefardí de la Universidad de Castilla-La Mancha (Toledo 1994) págs. 61-79. Las causas de «inhábiles» se hallan principalmente en AHN, Inq., legs. 119 y 120.
} 
les y de las actividades agrícolas. Los cristianos nuevos están considerados como unos «advenedizos» y heredan las mismas críticas formuladas contra sus antepasados judíos. Escuchemos a nuestros dos cronistas. Así dice Bernáldez:

[El grupo de los conversos había alcanzado] muy gran riqueza y vanagloria de muchos sabios e doctos e obispos e canónigos e frailes e abades e sabios e contadores e secretarios e factores de reyes e de grandes señores ... todos vivían de oficios holgados, y en comprar y vender no tenían conciencia con los cristianos. Nunca quisieron tomar oficios de arar ni cavar, ni andar por los campos criando ganados, ni lo enseñaron a sus fijos, salvo oficios de poblados, y de estar asentados ganando de comer con poco trabajo.

Y esta es la opinión de Palencia:

[Son individuos] extraordinariamente enriquecidos por raras artes, ensorbecidos y aspirando con insolente arrogancia a disponer de los cargos públicos, después que por dinero y fuera de toda regla habían logrado la orden de caballería hombres de baja extracción, acostumbrados a los más viles menesteres... ${ }^{3}$.

Ambos testimonios, fuertemente impregnados de antisemitismo, no dejan de tener un trasfondo de verdad histórica y de realidad social. No cabe duda de que en las comunidades judeoconversas existe una importante clase media productiva, dentro de la cual se hallan los artesanos, los comerciantes y las profesiones liberales, así como una élite reducida que gira en torno al poder local y nacional.

Por lo que se refiere al final del siglo XV, poseemos dos listas: una de 503 personas y de 101 oficios para la ciudad de Toledo y otra de 340 personas y de 77 oficios para su arzobispado.

Lo que llama la atención en primer lugar es la escasa representatividad del sector primario. Los judeoconversos casi no intervienen en las actividades productivas de materias no transformadas como la agricultura, la pesca o la ganadería. Dicho

${ }^{3}$ Ambos textos los recoge A. Domínguez ORTIZ, Los judeoconversos en España y América (Madrid 1971) págs. 22-23. 
sector alcanza el $0,7 \%$ de la actividad socioprofesional en Toledo y el $0,1 \%$ en su arzobispado. Volvemos a encontrar, pues, la situación descrita por Bernáldez para la época de los Reyes Católicos. No obstante, si los judeoconversos no se dedican directamente a las tareas agrícolas, es muy probable que algunos posean tierras (vides, olivares, heredades, etc.) y ganado (cabras, merinos, etc.).

Al contrario, el sector secundario -actividades productivas de materias transformadas- está muy desarrollado y representa un $64 \%$ en Toledo y un $68,8 \%$ en su arzobispado.

Como era de esperar, predomina la actividad textil que se organiza principalmente en torno al trabajo de la lana y de la seda. Salvo contadas excepciones, se pone gran empeño en el producto acabado, la transformación y la venta a costa de la producción. Los judeoconversos toledanos parecen interesarse por la comercialización de la seda y por la búsqueda de una clientela acomodada atraída por la artesanía de lujo.

Profesiones más representadas:

$\begin{array}{ll}\text { Toledo } & \text { Arzobispado de Toledo } \\ \text { sastres (20 de 165) } & \text { sastres (29 de 95) } \\ \text { toqueros (19 de 165) } & \text { tundidores (20 de 95) } \\ \text { sederos (17 de 165) } & \text { tintoreros (9 de 95) }\end{array}$

La artesanía del cuero emplea un $11,9 \%$ en Toledo y un $28 \%$ en su arzobispado. En el siglo XV los cueros toledanos suelen proceder de las afueras y de los montes de Toledo y se preparan luego en las villas de Sonseca, Ajofrín o Cuerva. Los tundidores instalados a orillas del Tajo trabajan las pieles que les proporcionan los mataderos municipales o los particulares.

Profesiones más representadas:

$\begin{array}{ll}\text { Toledo } & \text { Arzobispado de Toledo } \\ \text { borceguineros (16 de 60) } & \text { zapateros (59 de 95) } \\ \text { chapineros (15 de 60) } & \text { guanteros (14 de 95) } \\ \text { zapateros (14 de 60) } & \end{array}$

La artesanía del metal representa un $14,9 \%$ en Toledo y un $8,5 \%$ en su arzobispado. Cabe subrayar aquí la importancia de las actividades relacionadas con los metales preciosos. La ciu- 
dad de Toledo es famosa por sus armeros, especializados en la confección de espadas, cuyas hojas llegan de Vizcaya y de Milán (Italia), así como por sus plateros y sus doradores que realizan suntuosas obras de damasquinado.

Profesiones más representadas:

Toledo

plateros (42 de 75)

joyeros (17 de 75)
Arzobispado de Toledo

plateros (16 de 69)

herreros (7 de 69)

Además de las señaladas (industria textil, del cuero y de los metales preciosos), existe una artesanía variada que agrupa los oficios de la construcción (albañil, pintor, etc.), de la cera (candelero, cerero, etc.), de la alimentación (confitero, pastelero, etc.), de la alfarería (alfarero, tornero, etc.), etc.

Lógicamente, la hipertrofia del sector secundario se acompaña de la atrofia del sector terciario que representa un $35 \%$ en Toledo y un $31,2 \%$ en su arzobispado.

La actividad comercial representa un $12,9 \%$ en Toledo y un $11,3 \%$ en su arzobispado. En dicho sector, hay que subrayar el predominio absoluto del textil y de las especias.

Profesiones más representadas:

Toledo

mercaderes (36 de 65)

especieros (14 de 65)
Arzobispado de Toledo

mercaderes ( 8 de 33 )

mesoneros (6 de 33)

El sector de los servicios emplea un $11,9 \%$ en Toledo y un $7,1 \%$ en su arzobispado. A primera vista puede sorprender el número de criados conversos que están al servicio de correligionarios ricos e incluso de miembros de la aristocracia. En el arzobispado de Toledo, entre las sesenta y tres personas que trabajan en los servicios, nueve son criados y uno mozo de espuelas. Las profesiones liberales tradicionalmente reservadas a los judíos están muy bien representadas a través del derecho (escribanos, abogados, notarios, etc.) y de la medicina (cirujanos, físicos, apoticarios, albéitares, bachilleres en medicina, etc.).

El sector de la gestión financiera y de los oficios públicos aparece, con toda evidencia, como un sector minoritario que 
representa un $10 \%$ en Toledo y un $1,5 \%$ en su arzobispado. La ausencia de regidores, alcaldes mayores, alcaides, etc., no significa que los judeoconversos no participen de la vida social y política de las ciudades de Castilla. Es obvio que su influencia, atestiguada desde principios del siglo XV, fue obstaculizada momentáneamente por la represión inquisitorial de los años 1480-1520.

Profesiones más representadas:

$$
\begin{array}{ll}
\text { Toledo } & \text { Arzobispado de Toledo } \\
\text { arrendadores (15 de 51) } & \text { mayordomos (2 de 5) } \\
\text { cambiadores (12 de 51) } & \text { jurado (1 de 5) }
\end{array}
$$

De esta manera, podemos establecer una primera tipología socioprofesional de las comunidades conversas a finales del siglo XV. Esta se carateriza por: 1) la no representatividad del sector primario; 2) la hipertrofia del sector secundario, con un peso considerable de las profesiones relacionadas con la actividad textil (actividad que alcanza un $51 \%$ del conjunto del sector en Toledo y un $40,7 \%$ en su arzobispado); y 3) la atrofia del sector terciario con una preponderancia de la actividad comercial y financiera que representa un $56 \%$ del conjunto del terciario en Toledo y un $38,1 \%$ en su arzobispado.

Recapitulemos todo ello con un cuadro sinóptico.

\section{Cuadro por sector}

$\begin{array}{lrc} & \text { Toledo } & \text { Arzobispado de Toledo } \\ \text { Agricultura } & 0,7 \% & 0,1 \% \\ \text { Textil } & 32,6 \% & 28,0 \% \\ \text { Cuero } & 12,2 \% & 28,0 \% \\ \text { Metal } & 14,9 \% & 8,5 \% \\ \text { Artesanía diversa } & 4,5 \% & 4,1 \% \\ \text { Comercio } & 12,9 \% & 11,3 \% \\ \text { Servicios } & 12,0 \% & 18,5 \% \\ \text { Gestión económica } & & \\ \quad \text { y financiera } & 6,7 \% & 1,1 \% \\ \text { Oficios públicos } & 3,3 \% & 0,2 \%\end{array}$

Composición del sector secundario

$\begin{array}{ccc} & \text { Toledo } & \text { Arzobispado de Toledo } \\ \text { Textil } & 51,0 \% & 40,8 \% \\ \text { Cuero } & 18,5 \% & 40,8 \%\end{array}$



Metal
$23,3 \%$
$12,4 \%$
Diversos
$7,2 \%$
$6,0 \%$

Composición del sector terciario

$\begin{array}{lrc} & \text { Toledo } & \text { Arzobispado de Toledo } \\ \text { Comercio } & 36,9 \% & 33,9 \% \\ \text { Servicios } & 34,0 \% & 61,1 \% \\ \text { Gestión económica } & & \\ \quad \text { y financiera } & 19,4 \% & 4,2 \% \\ \text { Oficios públicos } & 9,7 \% & 0,9 \%\end{array}$

A partir de las causas de «inhábiles» he elaborado para la primera mitad del siglo XVI una lista representativa de 924 individuos y de 138 oficios, títulos y cargos honoríficos. Primero señalo los porcentajes por sectores de actividad socioprofesional, y a continuación comparo los resultados obtenidos con los de las listas de finales del siglo XV. Cabe preguntarse si hubo cambios notables a lo largo de esos dos períodos y cuáles son las nuevas tendencias que se dejan entrever.

En el período considerado, el sector primario representa el $6,5 \%$ del conjunto de la actividad profesional, el sector secundario el $15,8 \%$, el sector terciario el $73,1 \%$ y el clero el $4,6 \%$. Recapitulemos con un cuadro sinóptico:

Cuadro recapitulativo por sector

\begin{tabular}{|c|c|c|c|}
\hline $\begin{array}{l}\text { Agricultura, pesca, } \\
\text { ganadería }\end{array}$ & $6,5 \%$ & $\begin{array}{l}\text { Comercio } \\
\text { Textil }\end{array}$ & $\begin{array}{r}22,5 \% \\
7,2 \%\end{array}$ \\
\hline Cuero & $5,6 \%$ & Gestión económi- & \\
\hline Servicios & $25,9 \%$ & ca y financiera & 19,1 \\
\hline Metal & $1,5 \%$ & Oficios públicos & 5,6 \\
\hline Diversos & $1,5 \%$ & Clero & 4,6 \\
\hline
\end{tabular}

Composición del sector secundario

$\begin{array}{llll}\text { Textil } & 45,5 \% & \text { Metal } & 9,6 \% \\ \text { Cuero } & 35,3 \% & \text { Diversos } 9,6 \% & \end{array}$

Composición del sector terciario

$\begin{array}{lllr}\text { Comercio } & 30,8 \% & \begin{array}{c}\text { Gestión económi- } \\ \text { ca y financiera }\end{array} & 26,2 \% \\ \text { Servicios } & 35,3 \% & \text { Oficios públicos } & 7,7 \%\end{array}$


Un vistazo a estos porcentajes permite hacer hincapié en las diferencias fundamentales que existen entre los años finales del siglo XV y los de mediados del siglo XVI. En efecto, la sociología conversa cambió totalmente entre esos dos períodos.

El sector primario que representaba un $0,5 \%$ a finales del siglo XV, pasa a un $6,5 \%$ a mediados del siglo XVI. El sector secundario -cuyo peso considerable a finales del siglo XV se explicaba por la gran proporción de cristianos nuevos de origen judío recién convertidos entre los artesanos urbanos del textil, del cuero, del metal y de la construcción- pasa por término medio de un $66,4 \%$ a un $15,8 \%$. En cuanto al sector terciario, sufre la evolución inversa, pasando de un $33,1 \%$ a un $73,1 \%$. El clero, ausente hasta ahora, hace su aparición en el abanico de las profesiones con un $4,7 \%$.

La aparición de los descendientes de condenados en los medios agrícolas y eclesiásticos es reveladora del esfuerzo de integración en los medios cristianos nuevos después de la catástrofe de fines del siglo XV (fase de intensa represión inquisitorial) y traduce el dinamismo económico de la minoría conversa.

El sector secundario, a pesar de su fuerte disminución, no presenta diferencias de composición entre el final del siglo XV y la mitad del siglo XVI. La actividad textil (46 y $45,5 \%)$ se sitúa muy por encima de la artesanía del cuero $(29,6 \%$ y $35,3 \%)$ y del metal $(17,8 \%$ y $9,6 \%)$.

No ocurre lo mismo con el sector terciario que no sólo conoce un alza espectacular sino también una modificación interna a lo largo de todo el siglo XVI. La actividad comercial sigue siendo muy importante $(35,4 \%$ y $30,8 \%)$, el sector de los servicios se hunde $(47,5 \%$ y $35,3 \%)$ y el sector de la gestión económica y financiera conoce un desarrollo sin precedentes $(11,8 \%$ a fines del siglo XV, $29,5 \%$ en el siglo XVI). Para nuestra población anterior a 1500, los sectores del comercio y de la gestión económica y financiera alcanzan el $47 \%$ del conjunto del terciario, cifra en sí muy elevada, pero que alcanza en las listas del siglo XVI la aplastante proporción del $57 \%$.

Por una parte, asistimos a un incremento de las carreras administrativas que confieren honra y prestigio (regidor, jurado, escribano público, etc.); por otra parte, a una disminución de las tradicionales profesiones liberales relacionadas con el dere- 
cho y la medicina más particularmente, y del servicio doméstico (escudero, criado, paje, etc.). En cambio, los escribientes suelen ser siempre muy numerosos (el 16\% del total de los servicios en el siglo XVI). Así pues, en el siglo XVI los judeoconversos «inhábiles» gravitan esencialmente en los medios del comercio, de la gestión económica y financiera y de la administración.

¿El modelo que acabamos de señalar puede extenderse al conjunto de la población judeoconversa del siglo XVI? Los archivos del Santo Oficio conservan un padrón de los conversos de Ocaña elaborado en 1537 por los inquisidores de Toledo. A diferencia de las listas de «inhábiles» que sólo empadronan a los descendientes de condenados, o sea los conversos «marcados» por la huella inquisitorial, el censo de Ocaña abarca la totalidad de los cristianos nuevos de la ciudad, moriscos inclusive (nueve vecinos) ${ }^{4}$. Conocemos treinta y siete profesiones de los noventa y cinco vecinos censados. Los diferentes sectores de actividad profesional se presentan como sigue:

$\begin{array}{lrlr}\text { Agricultura } & 0 \% & \text { Comercio } & 12,7 \% \\ \text { Textil } & 16,8 \% & \text { Servicios } & 16,2 \% \\ \text { Cuero } & 24,2 \% & \text { Gestión económica } \\ & & \text { y financiera } & 0 \% \\ \text { Metal } & 16,8 \% & \text { Oficios públicos } & 1 \% \\ \text { Artesanía diversa } & 7,3 \% & \text { Clero } & 5 \%\end{array}$

Volvemos a encontrar aquí el perfil socioprofesional de los judeoconversos «habilitados» por la Inquisición de Toledo a fines del siglo XV (1495 y 1497), que se caracterizaba por la inexistencia del sector primario, la hipertrofia del sector secundario $(65 \%)$ y la atrofia del sector terciario $(35 \%)$. Por lo que se refiere a la composición de dicho sector, podemos notar que la actividad más desarrollada es la de los servicios, y que el sector de la gestión económica y financiera no emplea a nadie.

La población judeoconversa de la Ocaña de la primera mitad del siglo XVI no conoce el dinamismo económico que habíamos visto antes. Se trata sin duda de factores de coyuntura económica y de las repercusiones de la primera fase de represión inquisitorial. Ahora bien, hay que precisar que a través de las listas y de las causas de «inhábiles» del siglo XVI sólo nos acer-

${ }^{4}$ AHN, Inq., leg. 120, exp. 39. 
camos a una élite judeoconversa perfectamente integrada en una economía a la vez semirrural, agrícola y comercial, y que gravita alrededor de los concejos y de las administraciones locales.

Desde finales del siglo $\mathrm{XV}$, esta élite conversa ya debía de poseer los medios económicos y sociales que le permitieran en adelante superar rápidamente los èfectos de la catástrofe de los Reyes Católicos. Huelga decir que la tipología socioprofesional de los judeoconversos de la Mancha y de Castilla la Nueva se ha modificado considerablemente entre el final del siglo XV y la mitad del siglo XVI, lo que muestra el dinamismo y la vitalidad económica de estos grupos. Sin embargo, este desarrollo económico no tuvo las mismas repercusiones en el conjunto de la comunidad judeoconversa. Por una parte, la masa conversa tuvo muchas dificultades para vencer los efectos catastróficos de la primera ofensiva inquisitorial; por otra, la élite conversa pronto se integró en la sociedad mayoritaria cristiana vieja. ¿Despegue de doble velocidad?

Como lo ha demostrado muy acertadamente el historiador Gutiérrez Nieto la sociedad española moderna es una sociedad de tipo «castizo-estamental» 5 . Como los demás países europeos, se presenta bajo la forma de una estructura jerarquizada que consta de tres estamentos: la nobleza, el clero y el grupo de los pecheros, es decir los individuos no hidalgos que pagan el pecho. Sin embargo a la oposición noble/pechero que obedece a una terminología de estructura estamental cabe añadir la oposición cristiano viejo / cristiano nuevo que obedece a una terminología de estructura de castas. Los individuos que ejercen oficios «viles y mecánicos» así como los individuos que descienden de «raza de moros o judíos o de condenados por la Inquisición» se hallan excluidos de las esferas del honor y del prestigio social. España posee pues un doble sistema de exclusión honorífica: la hidalguía del linaje y la limpieza de la sangre.

A partir de mediados del siglo XVI asistimos a un cambio capital en las relaciones entre el trabajo y el honor. Salvo el trabajo de la tierra y el ideal de vida rentista, la atividad comercial y los oficios artesanales están considerados como «ofi-

5 J. L. GutiérRez Nieto, «Estructura castizo-estamental de la sociedad castellana en el siglo XVI», Hispania 127 (1973) págs. 519-563. 
cios viles y mecánicos», marcados a menudo por el estigma judaico y, por consiguiente, incompatibles con la nobleza. En la mentalidad hidalguista de la época, la palabra labrador se vuelve sinónimo de cristiano viejo, mientras que la palabra mercader evoca al cristiano nuevo y un modo de vida burgués opuesto al ideal de vida nobiliario.

Tal connotación negativa aparece claramente en las palabras de este letrado de Almagro que declara en 1537 que el término mercader se suele emplear para insultar a una persona y demostrar que viene de una "generación diferente»:

... e intitulándolos de nombres de mercaderes, no embargante que la mayor parte de los dichos sus partes no vivían del trato de mercaderías, salvo de sus haciendas y ganados y de labrar y criar y de sus heredades, y algunos de ellos eran letrados y personas honradas y principales que vivían de oficios limpios y honestos, por manera que intitulándolos mercaderes, aunque eran hombres honestos y de honra, solamente lo hacían por injuriar oprobio de los dichos sus partes, dando a entender que venían de una generación diferente de la de los otros vecinos de la dicha villa para que fuesen conocidos y diferenciados ${ }^{6}$.

Por decirlo de alguna manera los conversos eran doblemente impuros: impuros por su origen etnicorreligioso e impuros por su actividad profesional. No olvidemos que mediante la «limpieza de oficios», la sociedad española creó una barrera ideológica entre la nobleza y el resto de la población. J. A. Maravall, entre otros, ha mostrado que la exclusión por motivo de villanía tuvo un impacto social mucho más importante que la exclusión por motivo de mancha étnica. Parece ser que un $80 \%$ de la población quedó apartada de la sociedad por culpa de estas medidas segregacionistas?

Para llegar a ser miembro de la élite, para formar parte de los "principales» como se decía entonces, era preciso gozar de cierto estatuto jurídico, de cierta situación económica y de cierto poder político. Cada uno de estos factores era necesario

${ }^{6}$ J. LóPez-SAlAzAR PÉREZ, «Limpieza de sangre y división en estados: el municipio de Almagro durante el siglo XVI», Studia Historica: Historia Moderna 12 (1994) págs. 157-167: pág 162.

7 J. A. MARAVAlL, Poder, honor y élites en el siglo XVII ( $3^{\mathrm{a}}$ ed. Madrid 1989) págs. 115-170. 
pero ninguno era suficiente: de su asociación dependía la pertenencia a la nobleza ${ }^{8}$. Como ya he dicho los judeoconversos imitaron los valores imperantes en la sociedad dominante, ingresando en la agricultura y en la iglesia y adquiriendo cargos honoríficos. De esa manera pudieron integrarse en la dinámica social de la mayoría. Pero no por eso abandonaron el comercio, base exclusiva de su riqueza, como a veces se ha dicho un tanto apresuradamente. Ilustremos este aspecto con algunos ejemplos sacados de las causas de «inhábiles».

Luis Daza (1507?-1556), vecino de Alcázar de Consuegra, era nieto del escribano Juan Daza, condenado por la Inquisición. A lo largo de su vida profesional, desempeñó los cargos de mercader de seda y de paños, de mayordomo del pan en el priorazgo de San Juan, de recaudador de las rentas del prior de San Miguel, de arrendador de los diezmos de Alcázar de Consuegra, de alcalde ordinario con jurisdicción civil y criminal en la ciudad de Miguel Esteban, de escribiente de Gonzalo de Ubeda, vecino de Herencia, y de Juan de Alcázar, vecino de La Puebla de Almoradiel, y de preboste de la cofradía de San Sebastián ${ }^{9}$.

Juan Martínez Falcón (1486?-1556), hijo de Antón Ruiz, relajado por el tribunal toledano, fue sucesivamente mercader de paños y especiero en Alcázar de Consuegra, juez de causas civiles y criminales, alcalde de la Hermandad y arrendador de rentas del prior de San Juan ${ }^{10}$.

Diego Franco (1500?-1556), nieto del especiero Rodrigo Alonso, condenado por la Inquisición, se dedicó al comercio en Almodóvar del Campo, además de ser arrendador de la mitad de la renta del viento, de la carnicería y de la «montaracía que es de la mesa maestral», fiador de la renta de las minucias y recaudador de rentas reales (alcabalas) ${ }^{11}$.

Diego de Carrión (1500?-1541), vecino de Almagro e hijo de Alonso Alegre, condenado por hereje por la Inquisición, fue

$8 \mathrm{~J}$. PÉrez, «Réflexions sur l'hidalguía», en Hidalgos et Hidalguía dans l'Espagne des XVIe-XVIIIe siècles (Bordeaux 1989) págs. 11-22.

9 AHN, Inq., leg. 119, exps. 13 y 22.

10 AHN, Inq., leg. 119, exp. 47.

11 AHN, Inq., leg. 119, exps. 25 y 26. 
alcabalero del viento, arrendador de la encomienda de Almagro y mayordomo de la cofradía de San Bartolomé. Su hija, Elvira Gómez, casó con el platero almagreño, García de Villanueva ${ }^{12}$.

Francisco Marín ( $1480-1552$ ?), vecino de Cuerva, era hijo del zapatero Juan Marín, condenado por la Inquisición. A lo largo de su vida, combinó la actividad comercial con la gestión financiera, siendo arrendador de rentas variadas (pescado, carne, frutos secos, madera, carbón, etc.), y de la especiería y de los diezmos de los capellanes de la capilla del rey ${ }^{13}$.

Esta mezcla de actividades «marcadas» y no «marcadas» en el seno de varios linajes conversos tiende a demostrar que el proceso de integración no resultaba incompatible con el mantenimiento de servicios específicos. De ahí la paradoja que encubre la identidad conversa: por una parte, el grupo de los neófitos aprovechó todos los resortes que ofrecía la sociedad mayoritaria, imitando sus pautas culturales y sociales (honor hidalgo, títulos honoríficos, carrera de letrados, inversión en la tierra, etc.); por otra, siguió manteniendo su singularidad a través de solidaridades familiares, económicas y clientelares específicas (endogamia matrimonial, compañías comerciales, etc.). El converso ofrece pues la doble faceta de la identidad y de la alteridad, o mejor dicho de una identidad que puede cobrar aire de diferencia o de una diferencia que puede cobrar aire de identidad.

12 AHN, Inq., leg. 119, exp. 30 y leg. 120, exp. 43.

13 AHN, Inq., leg. 119, exps. 46 y 50. 


\section{APÉNDICE 1: FAMILIA ALCARAZ}

A. Hijos de Rui González de Alcaraz y de Leonor González ${ }^{1}$ :

1. Gonzalo de Alcaraz (1458?- d. 1511) ${ }^{2}$

2. Álvaro de Alcaraz

3. Francisco de Alcaraz (1461?- d. 1511) ${ }^{3}$

4. Pedro de Molina (1463?- d. 1511) ${ }^{4}$

5. Diego de Alcaraz (1465? - d. 1511) ${ }^{5}$

6. Alonso de Alcaraz

7. Julián de Alcaraz

8. María de Chinchilla = Juan de Chinchilla

9. Mencía de Alcaraz $=$ Alonso de Cáceres

10. Juan de Alcaraz $=$ Francisca de Toledo (vid. $B$ infra)

11. Hernando de Alcaraz (1456?- d. 1511) ${ }^{6}=$ Guiomar González ${ }^{7}$ (vid. C infra)

B. Hijos de Juan de Alcaraz y de Francisca de Toledo (A.10 supra):

1. Hernando de Alcaraz (1510?- d. 1511) ${ }^{8}$

2. Diego de Alcaraz (1508?- d. 1551) ${ }^{9}=$ ?

3. Álvaro de Alcaraz (1506? - d. 1551) ${ }^{10}$

4. María de Alcaraz $=$ Mateo Verdugo ${ }^{11}$

1 Vecinos de Ciudad Real. Relajados por la Inquisición de Toledo; enterrados en la iglesia de San Francisco.

2 Vecino de Daimiel. Elector de alcaldes y regidores, veedor de la casa del pregón, obligado de la carnicería, arrendador de la tercia del vino de Daimiel y alcalde de la cofradía de Nuestra Señora de Daimiel.

3 Vecino de Daimiel; en 1511 vive en Ayamonte (provincia de Huelva). Especiero y arrendador de las tercias del vino de Daimiel.

${ }_{4}^{4}$ Vecino de Daimiel; en 1511 vive en Tavira (Portugal). Especiero y arrendador de las tercias del vino de Daimiel.

5 Vecino de Daimiel. Elector de alcaldes y regidores, repartidor de alcabalas y pechos reales, obligado de las carnicerías de Daimiel y mayordomo de la cofradía de Nuestra Señora de Daimiel.

6 Vecino de Daimiel. Mercader y mayordomo de Nuestra Señora de Daimiel.

7 Hija de Pedro González Trejo, condenado por la Inquisición.

8 Vecino de Daimiel. Abastecedor de las carnicerías de Daimiel y de Torralba y hacedor de paños.

9 Vecino de Daimiel. "Trata en paños y herraje»; su hijo Juan Bautista de Alcaraz fue clérigo de la capilla de San Pedro de la catedral de Toledo.

${ }^{10}$ Vecino de Daimiel. Abastecedor de las carnicerías de Daimiel y de Torralba, hacedor de paños, «labra por pan poca cosa».

${ }^{11}$ Labrador, vecino de Daimiel. 
C. Hijos de Hernando de Alcaraz y de Guiomar González (A.11 supra):

1. Isabel Rodríguez (1506?-1551?) ${ }^{12}=$ Juan de Córdoba

2. Diego de Alcaraz (1493?- d. 1546) ${ }^{13}$

3. Rodrigo de Alcaraz (1494?- d. 1544) ${ }^{14}=$ Angelina Villarreal

4. Beatriz de Alcaraz (1502?- d. 1541) ${ }^{15}=$ Juan de Toledo 16

5. Juan de Alcaraz (1503?- d. 1550) ${ }^{17}=$ ?

6. Francisco de Alcaraz

7. Leonor de Alcaraz (1497?- d. 1550) ${ }^{18}=1$ ) licenciado de la Cruz; 2) Alonso de Ayala ${ }^{19}$

8. Costanza de Alcaraz

12 Vecina de Daimiel; viuda del bachiller Juan de Córdoba.

13 Vecino de Daimiel. Repartidor del pedido de San Miguel de Daimiel, arrendador de las rentas del arzobispo, arrendador de las tercias del vino, procurador del concejo, mayordomo de Nuestra Señora de Daimiel y alcalde y mayordomo de la Caridad de Daimiel.

14 Vecino de Daimiel. Nombrado por el Concejo para comprar pescado y sardinas para la Casa del peso, veedor de la Casa del peso, arrendador de la tercia del pan y del vino, repartidor del pedido de San Miguel, elector de los oficios de alcaldes y regidores, alcalde y mayordomo de la Caridad de Daimiel, escribano de Nuestra Señora de Daimiel y cofrade de la cofradía de mercaderes de San Roque.

${ }^{15}$ Vecina de Daimiel.

16 Nieto de condenado. Alcalde ordinario y mayordomo de cofradías en Daimiel.

17 Vecino de Daimiel. Regidor.

18 Vecina de Daimiel.

${ }^{19}$ Hijo de Rodrigo de Ayala, contador de la orden de Calatrava, y de Teresa Rodríguez, condenada por la Inquisición de Jaén (a. 1520). Bachiller y licenciado en derecho canónico, alcalde mayor en Vélez-Málaga, teniente de gobernador en el Campo de Calatrava, abogado en la Chancillería de Granada, en Arjona y en Almagro y juez de residencia en el condado de Cuenca. 


\section{APÉNDICE 2: FAMILIA ALCOCER}

A. Hijos de Alonso González Rubio ${ }^{1}$ y de ?:

1. Juan Álvarez (a. 1497 - a. 1545) ${ }^{2}=$ ? (vid. B infra)

2. Diego de Alcocer (a. 1515 - a. 1545) ${ }^{3}=$ Inés García $^{4}$ (vid. C infra)

3. Lope Ruiz (a. 1515 - a. 1545) ${ }^{5}=$ Isabel López ${ }^{6}$ (vid. D infra)

B. Hijos de Juan Álvarez y de ? (A.1 supra):

1. Alonso Álvarez

2. Inés Álvarez

C. Hijos de Diego de Alcocer y de Inés García (A.2 supra):

1. Juan de Alcocer (1512?- d. 1545) ${ }^{7}$

2. Alonso de Alcocer (a. 1515 - d. 1545) ${ }^{8}$

3. Aldonza Ruiz (a. 1515 - d. 1545) = Diego Vázquez ${ }^{9}$

4. Leonor García (a. 1515 - d. 1545) = Alonso Hernández de Villagarcía ${ }^{10}$

5. Hernando

6. Lope

7. María

D. Hijos de Lope Ruiz y de Isabel López (A.3 supra):

1. Alonso

2. María XV.

1 Vecino de La Puebla de Alcocer, relajado por la Inquisición a finales del siglo

2 Vecino de Ciudad Real; jabonero y trapero.

3 Vecino de La Puebla de Alcocer; tratante en paños y en otras mercaderías, mayordomo del conde de La Puebla y veedor de los paños.

${ }^{4}$ Hija de condenado por el Santo Oficio.

5 Vecino de La Puebla de Alcocer; mercader, boticario (paños, especias, seda, etc.).

${ }^{6}$ Hija de condenado por la Inquisición.

7 Vecino de La Puebla de Alcocer; en los años 1525-1530 vivía con don Francisco de Silva, hermano de Fernando de Silva, comendador de Otos y Guadalhorce, y con otros mercaderes. Cardador de paños a domicilio: «dixo que una frisa haze en su casa e que la carda e adereça, e otro pedaço que le fían lo lleba a vender».

${ }^{8}$ Vecino de La Puebla de Alcocer; cardador de paños y de frisas y arrendador de los diezmos del arzobispado.

9 Tundidor de paños, vecino de Almodóvar del Campo.

${ }^{10}$ Labrador, vecino de Almodóvar del Campo. 
3. Juan López (1515? - d. 1545) ${ }^{11}$

4. Diego de Alcocer o Ruiz (a. 1515 - d. 1545) ${ }^{12}$

5. Inés García (a. 1500 - d. 1545) ${ }^{13}=$ Hernán González ${ }^{14}$

6. Leonor López (a. 1500 - d. 1545) = 1) Marcos Díaz; 2) doctor Zalamea ${ }^{15}$

7. Aldonza Álvarez = Álvar González

8. Elvira García (a. 1515 - d. 1545) ${ }^{16}=$ Diego Sánchez ${ }^{17}$

9. Beatriz López (a. 1515 - d. 1545) ${ }^{18}$

11 Vecino de La Puebla de Alcocer; hacedor de frisas y pañuelos, trae la espada y monta a caballo.

12 Vecino de La Puebla de Alcocer; cardador de paños en casa de su hermano, trae la espada y monta a caballo.

13 Vecina de La Puebla de Alcocer.

14 Mercader (posee una tienda de paños), arrendador de la renta de lo blanco de las casas de don Pedro y albéitar.

15 Natural de Cáceres.

16 Trae oro y seda.

17 Trapero en La Puebla de Alcocer; fue notario y escribano público por Francisco Gascón.

18 Vive en casa de su hermano en La Puebla de Alcocer; lleva oro y seda. 


\section{APÉNDICE 3: FAMILIA ARANDA}

A. Hijos de Martín González Mazodia ${ }^{1}$ y de ?:

1. Pedro de Santesteban (a. 1487 - d. 1548) ${ }^{2}=$ ? (vid. B infra)

2. Diego de Santacruz (a. $1500-$ d. 1548) ${ }^{3}=$ ? (vid. C infra)

3. Rodrigo de Santillana (a. 1510 - d. 1548) ${ }^{4}=$ hija de Rui López (vid. D infra)

4. Juan de Aranda (a. 1505 - a. 1548) ${ }^{5}=$ Elvira Martínez ${ }^{6}$ (vid. E infra)

B. Hijos de Pedro de Santesteban (A.1 supra):

1. María Díaz (a. 1530 - d. 1548) = Antonio Sánchez ${ }^{7}$

C. Hijos de Diego de Santacruz (A.2 supra):

1. Hernando de Santacruz (a. 1530 - d. 1548) ${ }^{8}$

D. Hijos de Rodrigo de Santillana y de hija de Rui López (A.3 supra):

1. Martín de Aranda (a. 1500 - d. 1548) ${ }^{9}$

2. Rodrigo de Santillana (a. 1500 - d. 1548) ${ }^{10}$

3. Francisco de Santacruz (a. 1500 - d. 1548) ${ }^{11}$

4. Juan de Aranda (a. 1500 - d.1548) ${ }^{12}$

5. Leonor de Santacruz

E. Hijos de Juan de Aranda y de Elvira Martínez (A.4 supra):

1. Diego de Aranda (a. 1500 - d. 1548) ${ }^{13}=$ ? (vid. F infra)

1 Vecino de Ciudad Real, relajado in abstentiam por la Inquisición.

2 Natural de Ciudad Real y vecino de Almagro. Cambiador en Ciudad Real, mercader en Almagro.

3 Vecino de Almagro; mercader.

${ }^{4}$ Vecino de Villanueva de los Infantes; mercader.

5 Vecino de Almagro.

${ }^{6}$ Hija del mercader de Almagro, Diego Hernández, condenado por el Santo Oficio.

7 «Vive de su hazienda» en Almagro (rentero).

${ }^{8}$ Mercader en Almagro.

9 "Vivió de su ganado e fazienda» en Villanueva de los Infantes.

10 "Vive de su hazienda» en Villanueva de los Infantes.

11 «Vive de sus rentas» en Villanueva de los Infantes.

${ }^{12}$ Clérigo en Villanueva de los Infantes.

13 Vecino de Almagro. Bachiller por la universidad de Salamanca; teniente de gobernador en el Campo de Montiel; teniente de corregidor en Ubeda, Baeza, Jaén, Cuenca y Huete; juez de residencia en Ronda, Marbella y Ecija; juez 
2. Alonso de Molina (d. 1490 - d. 1548) ${ }^{14}=$ Teresa de Villarreal

3. Gonzalo de Molina (d. 1490 - d. 1548) ${ }^{15}=$ hija de Pedro Rodríguez

4. Catalina Hernández (d. 1490 - d. 1548) ${ }^{16}=$ Alonso González ${ }^{17}$

5. Isabel Rodríguez (d. 1490 - d. 1548) ${ }^{18}=$ Garcí Sánchez $^{19}$

6. Aldonza Martínez (d. 1490 - d. 1548) = Juan de las Doblas 20

7. María Martínez (d. 1490 - d. 1548) = Juan Escogido ${ }^{21}$

F. Hijos de Diego de Aranda (E.1 supra):

1. Juan de Aranda (1520? - d. 1548) ${ }^{22}$

2. Diego de Aranda

3. Ántonio de Aranda

4. Luis de Aranda

5. Elvira de Aranda

6. Martín de Aranda

pesquisidor en Salamanca, Zamora y en el reino de Murcia; y asesor de algunos alcaldes ordinarios de las villas y lugares del Campo de Calatrava.

14 Vecino de Almagro; mercader.

15 Vecino de Almagro; mercader: «compra y vende».

16 Vecina de Almagro.

${ }^{17}$ Mercader.

18 Vecina de Almagro

19 «Vive de su hacienda».

${ }^{20}$ Labrador en Baeza.

${ }^{21}$ Mercader en Almagro; su padre, Gonzalo Escogido, era veedor de paños en los años 1540 .

${ }^{22}$ Vecino de Almagro. Ha estudiado derecho en la Universidad de Salamanca. 


\section{APÉNDICE 4: FAMILIA PEÑA}

A. Hijos de Diego de Cáceres (a. 1480 - ?) ${ }^{1}$ y de ?:

1. Gómez de Cáceres (a. 1500 - a. 1583) ${ }^{2}$

2. Diego de Cáceres (a. 1500 - a. 1583$)^{3}$

3. Luis de la Peña (a. 1500 - a. 1583 ) ${ }^{4}=$ Catalina González ${ }^{5}$ (vid. $B$ infra)

B. Hijos de Luis de la Peña y de Catalina González (A.3 supra):

1. Diego de Cáceres (d. 1500 - ?) ${ }^{6}=$ hija de la mujer de Torres ${ }^{7}$

2. Luis de Cáceres (d. $1500-$ d. 1583) ${ }^{8}=$ ? (vid. C infra)

3. Pedro de Cáceres

4. Francisco de Cáceres (d. 1500 - d. 1583) ${ }^{9}$

5. Miguel de Cáceres

6. Juan de la Peña (1517 - d. 1583) ${ }^{10}=$ Marí López ${ }^{11}$ (vid. D infra)

7. Isabel de Cáceres $($ d. $1500-1583)=$ Francisco Núñez ${ }^{12}$ (vid. E infra)

8. María de Cáceres (d. 1500 - a. 1583) = Antonio García ${ }^{13}$

9. Luisa de Cáceres (d. $1500-$ d. 1583) = Jorge Gómez ${ }^{14}$

10. Catalina de la Peña (d. $1500-$ d. 1583) = Juan de $\mathrm{Paz}^{15}$

C. Hijos de Luis de Cáceres (B.2 supra):

1. María de Cáceres $=$ Lorenzo de Figueroa ${ }^{16}$

${ }^{1}$ Natural de Valverde; condenado por la Inquisición en Plasencia.

2 Vecino de Valverde; zapatero.

${ }^{3}$ Boticario en Candeleda.

${ }^{4}$ Natural de Valverde y vecino de Oropesa; labrador.

${ }^{5}$ Natural de Oropesa; hija de Juan Jiménez, zapatero cristiano nuevo.

${ }^{6}$ Labrador en Oropesa.

${ }^{7}$ La madre era viuda del tundidor de paños Pedro García.

${ }^{8}$ Labrador en Oropesa. Murió en las Indias.

${ }^{9}$ Zapatero que vive en Coria. Se fue a las Indias.

10 Vecino de Oropesa; zapatero, obligado de las carnicerías de Oropesa y mayordomo de la cofradía de Nuestra Señora de Oropesa.

"Hija de Diego López Arenales, vecino de Arenas.

12 Sastre en Jarandilla.

13 Tundidor de paños en Oropesa.

14 Boticario en Jarandilla.

${ }^{15}$ Sacristán de Candeleda.

${ }^{16}$ Escribano. 
D. Hijos de Juan de la Peña y de Marí López (B.6 supra):

1. Sebastián López (d. 1520 - d. 1583) ${ }^{17}=$ Ana López

2. Blas González (1543? - d. 1583) ${ }^{18}=$ Juana Martín

3. Juan de la Peña

4. Catalina González (d. $1520-$ d. 1583) = Fulano ${ }^{19}$

5. Ana López

6. Diego López (? - d. 1583) ${ }^{20}$

7. Marí López = Andrés González $\left(\right.$ d. 1520 - d. 1583) ${ }^{21}$

E. Hijos de Isabel de Cáceres y de Francisco Núñez (B.7 supra):

1. Juan de Cáceres (d. 1520 - d. 1583) ${ }^{22}$

\footnotetext{
17 Tundidor de paños en Oropesa.

${ }^{18}$ Labrador en Oropesa.

19 Trabajador de Oropesa.

20 En 1583 vive en casa de un boticario de Oropesa.

${ }^{21}$ Herrador en Colmenar.

22 Vive en casa de un escribano del conde de Oropesa.
} 


\section{APÉNDICE 5: FAMILIA RODRÍGUEZ DE PISA}

A. Hijos de Juan Rodríguez de Pisa ${ }^{1}$ y de ?:

1. Hernando de Pisa (a. $1480-$ ?) ${ }^{2}=$ ? (vid. B infra)

2. García de Pisa

3. Diego de Pisa (a. $1480-$ ?) ${ }^{3}=$ ? (vid. C infra)

4. Lope de Pisa $=$ ? (vid. D infra)

5. Manuel de Pisa (a. 1480 - ?) ${ }^{4}=$ ? (vid. E infra)

6. Men Rodríguez $=$ ? (vid. F infra)

7. Miguel de Pisa (a. 1480 - ?) ${ }^{5}=$ ? (vid. G infra)

8. Gonzalo de Pisa $=$ ? (vid. H infra)

9. Martín Rodríguez de Pisa = ? (vid. I infra)

B. Hijos de Hernando de Pisa (A.1 supra):

1. Isabel de Pisa

2. Catalina de Pisa

3. Marí González (d. 1480 -d. 1520) ${ }^{6}$

4. Juan de Pisa $=$ ? (vid. J infra)

C. Hijos de Diego de Pisa (A.3 supra):

1. Gonzalo de Pisa

2. Lope Franco

3. Alonso de Pisa (? - d. 1549) ${ }^{7}=$ ? (vid. K infra)

4. Juan Rodríguez de Pisa (1490 ? - d. 1549) ${ }^{8}$

5. Hernando de Pisa

D. Hijos de Lope de Pisa (A.4 supra):

1. Álvaro de Pisa

1 Vecino de Almagro, condenado y relajado por el Santo Oficio.

2 Vecino de Almagro, relajado; especiero.

3 Mercader condenado por la Inquisición.

${ }^{4}$ Bachiller en leyes.

5 Bachiller en leyes.

6 En los años 1520 es beata en Granada.

7 Vecino de Almagro; bachiller en leyes, alcalde de la Hermandad, alcalde de la Mesta (1544), repartidor de alcabalas, alcalde de cofradías religiosas en Almagro y arrendador de los diezmos del maestrazgo de Calatrava.

8 Vecino del Viso del Marqués; alcalde de la Hermandad del Viso, alcalde de la cofradía de San Sebastián (1546), alcalde de Nuestra Señora de la Visitación (1549), regidor del concejo y rentero: «vive de su labrança y tiene un poco de ganado». 
2. Gonzalo de Pisa (a. 1500 - d. 1549) ${ }^{9}$

3. Andrés de Pisa (a. 1500 - d. 1549) ${ }^{10}$

E. Hijos de Manuel de Pisa (A.5 supra):

1. Juan Rodríguez de Pisa (a. 1500 - d. 1549) ${ }^{11}$

2. García de Pisa (a. 1500 - d. 1549) ${ }^{12}$

F. Hijos de Men Rodríguez (A.6 supra):

1. Pedro de Pisa

2. Gonzalo de Pisa

G. Hijos de Miguel de Pisa (A.7 supra):

1. Bernardo de Pisa (a. 1500 - d. 1549) ${ }^{13}$

2. Juan Rodríguez de Pisa

3. Diego Rodríguez de Pisa (a. 1500 - d. 1549) ${ }^{14}=$ María de Horozco 15

4. García de Pisa

5. Francisco de Pisa (a. 1500 - d. 1549) ${ }^{16}$

6. Julián de Pisa (a. 1500 - d. 1549) ${ }^{17}$

7. Antonio de Pisa (a. 1500 - d. 1549) 18

H. Hijos de de Gonzalo de Pisa (A.8 supra):

1. Juan Rodríguez de Pisa $=$ ? (vid. L infra)

I. Hijos de Martín Rodríguez de Pisa (A.9 supra):

1. Pedro Gonzalo de Pisa

${ }^{9}$ Bachiller en leyes y regidor en Almagro.

${ }^{10}$ Bachiller en leyes y regidor en Almagro.

11 Vecino de Cuenca en 1549; regidor, guarda mayor y procurador.

12 Vecino de Cuenca; regidor de Huete.

13 Vecino de Almagro; elector de oficios de alcaldes y regidores, arrendador de rentas y mercader.

14 Vecino de Almagro; licenciado en leyes por la Universidad de Salamanca, abogado, juez trayendo vara por el Campo de Calatrava (causas civiles y criminales), teniente de gobernador, juez ejecutor de lo debido a su majestad de alcabalas y asesor de jueces.

15 Natural de Toledo; hija de Fernando de Horozco, alguacil de la Inquisición.

${ }_{16}$ Vecino de Almagro; licenciado en leyes, abogado en corte, teniente de gobernador en el Campo de Calatrava, juez de residencia y asesor de alcaldes ordinarios.

17 Abogado en Huete.

18 Vecino de Granada; licenciado en leyes y abogado. 
J. Hijos de Juan de Pisa (B.4 supra):

1. Alonso de Pisa (d. 1500 - d. 1549) ${ }^{19}$

2. Andrés de Pisa (d. 1500 - d. 1549) ${ }^{20}$

3. Juan de Pisa (d. 1500 - d. 1549) ${ }^{21}$

4. García de Pisa (d. 1500 - d. 1549) ${ }^{22}$

5. Marcos de Pisa (d. 1500 - d. 1549) ${ }^{23}$

K. Hijos de Alonso de Pisa (C.3 supra):

1. Juan Rodríguez (d. 1500 - d. 1549) ${ }^{24}$

2. Hernando de Pisa

L. Hijos de Juan Rodríguez de Pisa (H.1 supra):

1. Gonzalo de Pisa (d. 1500 - d. 1549) ${ }^{25}$

2. Alonso de Pisa (d. 1500 - d. 1549) ${ }^{26}$

3. Bachiller de Pisa (d. 1520 - d. 1549) ${ }^{27}$

19 Vecino de Almagro; clérigo y beneficiado.

20 Vecino de Almagro; clérigo.

21 Vecino de Almagro; arrendador de rentas.

22 Vecino de Almagro; clérigo.

23 Vecino de Almagro; arrendador de rentas, notario y escribano de la judicatura del Campo de Calatrava.

24 Vecino de Almagro; bachiller en leyes y abogado.

25 Vecino de Almagro; arrendador de rentas.

${ }^{26}$ Arrendador de rentas en Almagro.

27 Bachiller en leyes y abogado. 


\section{APÉNDICE 6: FAMILIA VILLARREAL}

A. Hijos de Hernán García de Piedrabuena y de ? (a. 1460 - a. 1500) ${ }^{1}$ :

1. Rodrigo de Villarreal

2. Francisco de Piedrabuena

3. García de Piedrabuena

4. Diego de Villarreal ${ }^{2}=$ Juana González (vid. B infra)

B. Hijos de Diego de Villarreal y de Juana González (A.4 supra):

1. Juana García (? - d. 1573) = Gómez de Moya ${ }^{3}$

2. Catalina de Villarreal (? - a. 1573) = Diego de los Olivos ${ }^{4}$

3. Antón de Villarreal (? - a. 1573) ${ }^{5}=$ ? (vid. C infra)

4. Alonso de Villarreal $=$ ? (vid. D infra)

5. Lope Sánchez (? - a. 1573) ${ }^{6}$

6. Juan de Villarreal (? - a. 1573) ${ }^{7}=1$ ) ?; 2) Leonor de Villanueva $^{8}$ (vid. E infra)

7. Francisco de Villarreal $(1500 ?-\text { d. } 1573)^{9}=$ Catalina de Pisa (vid. $F$ infra)

8. Hernán García de Villarreal

9. Teresa de Villarreal (1500 ? - a. 1573) = Antonio de Molina ${ }^{10}$

10. Álvaro de Villarreal (1500 ? - a. 1573) ${ }^{11}=$ ? (vid. G infra)

11. Pedro de Villarreal

12. Gonzalo de Villarreal

1 Vecino de Ciudad Real, relajado por la Inquisición.

2 Regidor de Almagro, relajado por la Inquisición a finales del siglo XV.

${ }^{3}$ Escribano de La Calzada.

${ }^{4}$ Mercader y arrendador de rentas en Almagro.

5 Mercader en Almagro.

6 Vecino de Almagro; bachiller en leyes y abogado.

${ }^{7}$ Mercader en Almagro.

${ }^{8}$ Hija del caballero del Toboso y hermana de María de Villanueva.

9 Vecino de Almagro; «haze paños en su casa», obligado de las carnicerías de Almagro y de El Moral por mandamiento de don Juan Lorenzo, prior de Santa Cruz, encargado del ganado de Gaspar Rótulo (20.000 ovinos) y del bachiller Aranda (2.000 reses): "tenía cuidado de visitar los ganados y de llevarlos a la sierra y de arrendar las dehesas», recaudador del diezmo del pan de la mesa maestral en lugar de Gaspar Rótulo, tesorero de algunos particulares que tenían compañías de trato de carnicerías y otras mercadurías, mercader de lana y de ganado, "vive de su hazienda» (1548).

10 "Tratante que va e viene a Sevilla».

11 Vecino de Almagro; licenciado en medicina (Universidades de Salamanca y Valladolid), médico y físico. 
13. Isabel de Villarreal

14. Fulana de Villarreal (1500 ? - ?) = Bachiller de Pisa ${ }^{12}$

C. Hijos de Antón de Villarreal (B.3 supra):

1. Diego Sánchez de Villarreal (d. 1500 - d. 1573) ${ }^{13}$

2. Fulana $=$ Bachiller de Santa Cruz ${ }^{14}$

3. Juan de Villarreal (d. 1500 - ?) ${ }^{15}=$ hija del caballero del Toboso

D. Hijos de Alonso de Villarreal (B.4 supra):

1. Diego Sánchez de Villarreal (d. 1500 - ?) ${ }^{16}$

2. Antonio de Villarreal (1500 ? - d. 1565) ${ }^{17}$

3. Fulana de Villarreal $=$ Pedro Ramírez

E. Hijos de Juan de Villarreal (B.6 supra):

1. Antonio Sánchez de Villarreal (1503 ? - d. 1573) ${ }^{18}=$ Marí Díaz

2. Gonzalo Sánchez de Pisa (d. 1500 - a. 1548) ${ }^{19}$

3. Diego Sánchez

4. Hernando de Villarreal

12 Bachiller en leyes de Almagro.

13 Vecino de Almagro; regidor en 1543, procurador del común y del concejo de la villa, arrendador de la alcabala de la Hermandad (1541) y arrendador de rentas diversas.

14 Bachiller en medicina, médico en Almagro.

${ }^{15}$ Mercader en Almagro.

${ }^{16}$ Regidor en Almagro.

17 Vecino de Almagro; arrendador de rentas (tercias de la mesa maestral de Calatrava, tercias del vino de Almagro, etc.), obligado de las carnicerías de Almagro, elector de oficios reales, escribano de la Hermandad de Almagro, repartidor de alcabalas, escribano del Concejo, regidor en Almagro, vive de sus rentas (ganado + heredades), teniente de gobernador en La Calzada (justicia civil y criminal), alcalde de la cofradía de Nuestra Señora de la Concepción y diputado de la cofradía de la Madre de Dios.

18 Vecino de Almagro; posee un privilegio de la Chancillería de Granada «en que le hazen gracia y merced de que no le empadronen en el padrón de los pecheros durante el tiempo que este declarante sirvió a su majestad en las guerras de Italia», mayordomo de la cofradía de la Santísima Trinidad en Almagro, mayordomo de San Antón, mayordomo de Nuestra Señora de San Juan (1557) y juez de la cofradía de Nuestra Señora de los Llanos (1572).

19 Vecino de Almagro; señor de ganado. 
5. Alonso Sánchez de Villarreal (1508 ? - a. 1573) ${ }^{20}$

6. Marí Díaz (? - a. 1549) = Hernando de Horozco ${ }^{21}$

7. Catalina de Villarreal = Hernán García

F. Hijos de Francisco de Villarreal y de Catalina de Pisa (B.7 supra):

1. Juan Rodríguez (d. 1520 - d. 1573) ${ }^{22}$

2. Antonio de Villarreal

3. Juana

4. María

G. Hijos de Álvaro de Villarreal (B.10 supra):

1. Francisco de Villarreal

2. Antonio de Villarreal

3. Alonso de Villarreal

4. Jerónimo de Villarreal

5. Agustín de Villarreal

6. Juana de Villarreal

20 Vecino de Almagro; hombre de armas en Italia (1520-1525), escribano de la cofradía de San Pedro, escribano de las cofradías de San Pablo y de San Antón, alcalde de la cofradía de San Pedro, mayordomo de la cofradía de San Pablo, «vive de su hazienda» (1548)

21 Alguacil del Santo Oficio de Toledo.

22 Vecino de Almagro; clérigo presbítero. 


\section{RESUMEN}

A mediados del siglo XV los descendientes de los judeoconversos condenados por la Inquisición toledana diversificaron sus actividades socioprofesionales e imitaron los valores que imperaban en la sociedad dominante. Así se introdujeron en las actividades agrícolas, ingresaron en el clero y adquirieron cargos honoríficos, de manera que pudieron integrarse en la dinámica social de la mayoría. Pero no por eso abandonaron el comercio, base exclusiva de su riqueza, como a veces se ha dicho un tanto apresuradamente. Esa mezcla de actividades «marcadas» y no «marcadas» tiende a demostrar que el proceso de integración no resultaba incompatible con el mantenimiento de servicios específicos.

\section{SUMMARY}

In the mid-fifteenth century, the descendants of the Jewish converts condemned by the Toledo Inquisition diversified their economic and profesional activities by imitating the ruling classes. They became actively involved in agriculture, entered religious orders, and acquired honorary titles, to such degree that they were readily able to integrate into mainstream society. That notwithstanding, they did not at the same time abandon their commercial interests, which provided them with an economic mainstay. Integration into the mainstream of Spanish society was not incompatible with maintaining prior specific commercial interests. 